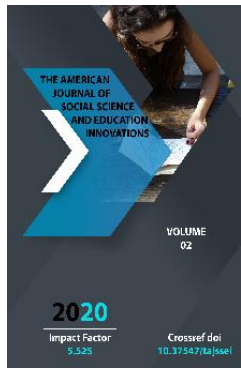

Journal Website: http://usajournalshub.c om/index,php/tajssei

Copyright: Original content from this work may be used under the terms of the creative commons attributes 4.0 licence.

\section{The Importance Of Functional Words Categories In Uzbek Language And Their Lingvo-Pragmatic Analysis}

Pardaev Azamat Bakhronovich, Doctor Of Philological Sciences, Professor Of The Department Of Uzbek Linguistics, Samarkand State University, Samarkand, Uzbekistan

Odinaev Bekkul Imamkulovich Researcher Of The Department Of Uzbek Linguistics, Samarkand State University, Samarkand, Uzbekistan

\title{
ABSTRACT
}

Identify the role of functional words in Uzbek language system, relation to content words, sources of enrichment and methods, historical and evolutionary development and determination of functionalstylistic and substantial-pragmatic features in speech.

\section{KEYWORDS}

Native language, wordscategories, linguistic system, semantic-methodological.

\section{INTRODUCTION}

The functional words are considered to be very sensitive to life changes and resourceful layer in all languages of the world. Therefore, for world linguisticsit is very important to determinethe place of functional words in the parts of speech system, identify rules of forming specialization of functional words, to highlight their ethnolinguistic, pragmalinguistic and psycholinguistic characterestics.

After achieving the country's independence, the further development of the native language, which is considered as the mirror of national traditions, has been raised to the level of the state policy. Preserving the native 
language, its enrichment, and necessity to work constantly on further enhancing its reputation has become a major issue of importance for our country's leader. Indeed, as our president pointed out: «First of all, nowadays, expanding the scope of application of the native language, learning deeply its historical roots and development of all aspects on scientific basis has become the most pressing issue»[1].

Thanks to independence Uzbek language has restored its reputation and has become one of the leaders among the Turkic languages [2]. Over the past several years many studies have been devoted on learning all stratums of our native language.In particular, we started to get rid of some Russian language standards imposed into our language grammatical structure. Uzbek language grammar was atoned from artificially "approximation" traits with Russian grammar. The certain successes were achieved in description of Turkish nature of our language, including the system functional wordscategories. However, we still do not have enough theoretical evaluation of functional words in our linguistics. Today, the generalization of these descriptions and interpretations on the basis of modern methodological principles, and evaluation of events based on new methods of scientific description has become a necessity.The views on these category words need theoretical development. The solution of this problem was not found yet not only in Uzbek linguistics, but in World linguistics as well, and it still remains the most disputed issue.Therefore, based on the recent achievements of functional words in world linguistics, according to the internal laws of our language, their classification and functional-semantic and pragmatic substantsial study is one of the most important issues of modern Uzbek linguistics.
It should be pointed out, as of today, functional word in Uzbek linguistics were described according to formal analysis principles. Nowadays, the formal analysis together with substantial interpretation principles - linguistic system and linguistic units are considered as good opportunities, and understanding these opportunities as an internal conflict integrity arising from various relations of linguistic unit is becoming a trend.In addition, irrespective of the fact if functional words are in linguistic phase or in speech phase, they were studied on the descriptive basis, so far seperate from the principles of static linguistic analysis activity and from speech process.Today, in our linguistics the pragmalinguistics - based on the principles of discursive analysis of language and speech units, the comprehensive analysis of pragmatic and stylistic characteristics during communicative speech process is becoming widely popular. Although, as of today there were several research works devoted to semantic-methodological characteristics of functional words, however, they missed the following: semantic common, functional limitations, discursive semanticstylistic parallels and differences, mutual exchange and there was no single source of studying contradiction cases with each other, substantiality connected with pragmatism in monolithic monographic form. In Uzbek language there are three types of approaches based on new methodological principles related to linguistic role and speech events of functional words - evaluation of previous, factual materials with the new criteria determines the relevance of the research.

\section{MATERIALS AND METHODS}

Starting with century linguistics as a result of the global gain pragmalinguistic, culturalinguistic, psycholinguistic influences 
function words were also examined from the point of view as a means of acting on the human psyche his cognitive world. For example, in the framework of the International Grant of the National Institute of Health MN 59321 linguists University of Pennsylvania and Ch.Sindi Dzh.Pennbeyker exploring the psychological characteristics of function words justified as the primary means of mental state of the person in the process of speech relationships [3]. Project participants of the European Council ERC-2011-AdG-295810 M.Zhonson (Sydney), E.Kristoff (Paris), D.Katrin (New Mexico), D.Emmanuel (Paris) in the study of function words studied voice paradigmatic forms, the ability to ability selection of function words when speech communication as one of the defining features of the intellectual development[4]. Since the 90 years of the twentieth century, fundamental research function words linguists Beijing University, which analyzed more than ten thousand words of Chinese language support as lingvokulturemy and created for learners of the language facilities[5] Ch.Naoko linguist Sophia University Tokyo, described more than seventy speech loads as decoration and compared with two hundred turns of phrase in the English language[6].

In studying semantic and grammatical structures of functional words in world linguistics, the research is conducted in the following priority areas:identify the role of functional words in linguistic system; identify statistics of functional words in certain language;substantiation of the process of functional words origin and their grammaticalization; determine interlanguage transposition; analyze pragmalinguistic, linguoculturological, psycholinguistic features; determine the role of functional words during speech communication process.
The content, units of functional words categories were studied in World linguistics5, as well in Uzbek linguistics and the research results were applied in the General description of Uzbek language formation, in scientific grammar and dictionaries, and in various study books compiled in accordance with different educations system's levels. These decriptions were implemented mainly on the basis widely spread traditional linguistic methods of $\mathrm{XX}$ century.In particular, this issue was studied in scientific works of such linguists as A.Kononov, Sh.Shoabdurahmonov, Kh.Berdiyorov, J.Muhtorov, R.Rasulov, T.Rustamov, D.Orinboeva. In the recent years, a series of separate studies were carried out dedicated to pragmatic and functional analysis of functional words by separate categories. In particular, in research works of such linguists as O.Bozorov, U.Rahimov, T.Turdiboev, Z.Isokov, Z.Burkhanovthe certain characteristics of functional words were studied. As a result, rich materials and information were collected in this directionThe implemented works in this direction were relatively discussed in detail in the first chapter.

The following approaches were used in the works dedicated to functional words:

1) from word as a seperate part of speech,

2) functional words as a tool between vocabulary and grammar,

3) functional word as a tool for decribinggrammatical meaning,

4) functional words as an object of stylistics.

The following methods were applied to cover the research subject:

- Comparative-historical method(origin of functional words ( etymology), development, its relations with content words during research process); 
- Method of synchronous formal description (determine the content of functional words categories, types of units structures, types of speech meaning);

- Comparative method (compare different generalities during process of determining similarity principles and differences);

- Method of distributive analysis (during process of detremining additional and contradictory distribution in generalities);

- Substantial analysis method (in determining gradual and other types of paradigmatic relations, general (linguistic) and private (speech) meaning relations);

- Discursive analysis method (during the process of determining pragmatic meanings of functional words structures in discourse (in speech communication considered as an activity);

- From statistical methods (during the process of determining speech frequency of some events).

Using example of functional words categories, mutual connection of obtained descriptions by methods of formal, substantial and discursive analysis of linguistic units, and it was proved that we could use methods of ensuring the continuity in other language units' decription as well;

new approach, that is, the learning methodics of functional words interlinked with formal, substantial and discursive analysis was worked out and practically implemented in the definition of concrete cases in Uzbek language;

As a result of application of formal, substantial and discursive methods together, in the concluding table of research "Content of functional words categories in Uzbek language and their substantial-pragmatic description" - functional words of Uzbek language were structurally classified as a taskform and their close parameters were identified.

\section{RESULT AND DISCUSSION}

The origin of functional words, their role in paradigm of parts of speech, and such issues as their relations with content words were theoretically substantiated; the role of grammaticalization case in transition of independent lexical units into functional words was identified, clarifying their general and private grammar meaning relations, it was proved that these units take third position in contradiction space between "word" and "morpheme";

the mutual transposition of functional words (auxiliary to linking words, linking words to particle, particle to linking word) was substantiated and the existence of presupposition sign in these tools was identified, and allocating graduonomic orders in each functional words categories, nexusperiphery relation in series was identified;

It was proved by examples, that functional words express various pragmatic subjects connected with uncovering illocutionary goal of the text's author. Reviving new text in particles, forming a task of attaching discourse spirit to it and development of new types of particles discursive particles were substantiated;

It has been described with exact examples, that as a result of expanding speech communication opportunities of Uzbek literary language, like other parts of speech functional words have been attracting new units, and their grammatical and pragmatic opportunities have been increasing; 
During independence years in the process of specialization of functional words the new sectorial directions were formed and developed, and their close linkages were described by examples. Also, the differentiation of formations out of functional words was analyzed and based on meaning it was proved that their pragmatic specialization process was going on.

The followings were substantiated: symbols and historical-etymological origin of each 616 pure and functional functional words used in modern Uzbek language, pure (original) or purposeful, orinin of functional functional words from wich parts of speech and their grammaticalization level, their belonging to category, or semantic-functional type and group, form appearance, single taskness or multitaskness, linkage to the adjacent categories, application scale, their methodical and within method sectoral uniqueness, more than 10 ontological characteristics with or without inherent presuppositional features contained in table"Content of functional words categories in Uzbek language and their substantial-pragmatic description", and results received through this table provides important scientific-theoretical information, history of language, genealogy of parts of speech, stylistics, speech culture, pragmalinguistics and grammar related to various aspects of text linguistics, theory of linguistics, and practical results of research were used to improve study books and guides created from abomentioned subjects;

As a result of the research during speech communication the stylistic activity of functional words has various meanings, and the followings were identified: speech status and condition of pragmatic(discursive) characteristics, personal psychological condition of speaker and listener, clear and hidden purpose additional information about its attitude (distinction, meaningfulness, positiveness, negativity, doubt, belief, claim, naturalness,extraordinariness and so on).

In functional units, we determined the followings: which word categories they developed from, in which phase ofgrammaticalizationthey are located likeёрдамчисимонлик,ёрдамчилашаётганли к,ёрдамчилашганлик and nonderivativeness, the main (primary) and adjacent (secondary) taskswere identified, framework of application and proposals and recommendations on their pragmatic features were worked out.

\section{CONCLUSION}

The tables created as a result of this research provides detailed description of functional words (auxiliary word, liking words, particles), their role in language and speech system, as well as importance in Uzbek conversational speech through explaining formal, substantial and pragmatic features. Materials thesis can be used to create teaching aids for seminars and workshops on the history and genealogy of language parts of speech, style of the Uzbek language, culture, language, and to write in the future monographs and textbooks on the semantic groups of function words and their paradigmatic syntagmatic relations semantic structure and pragmatic features.

\section{REFERENCES}

1. http://www.uza.uz/documents/alishernavoiy-nomidagi-toshkent-davlat-o'zbektili-va-adabiyoti-13-05-2016

2. MahmudovN., Begmatov E.Our language's yesterday and today // Uzbek Language and Literature.- Tashkent, 2010. -№5.-B.Z. 
Doi: https://doi.org/10.37547/tajssei/Volume02Issue09-96

3. Pennebaker, DJ. CH.Chung. The Psychological Functions of Function Words / Philadelphia: Linguistic Data Consortium, University of Pennsylvania / http://homepage.psy.utexas.edu / homepage /faculty/ pennebaker/ reprints/ Chung\&JWP.pdf .2014.

4. http://www.Iscp.net/persons/dupoux/pape rs/Johnson_CDD_2014_function_words improve_unsupervized_word_segmentatio n.ACL.pdf

5. http://www.aolifo.de/ Lectures of Function Words of Contemporary ChineseLanguage /现代汉语虚词讲义 / Peking University Press. 2005.

6. www.kodanshausa.com/authors/65... 